\title{
Rhinocerebral mucormycosis in diabetic patients. Review of a clinical case
}

\author{
Álvaro Villegas-Cisneros* and José Ernesto Miranda-Villasana \\ Hospital Regional Gral Ignacio Zaragoza, ISSSTE, Ciudad de México, México
}

\begin{abstract}
Rhinocerebral mucormycosis is a lethal opportunistic fungal infection. It is the most common presentation of this mycosis and has a higher prevalence in diabetic patients, originating in the mucosa of the nasal sinuses after the inhalation of fungal spores. The study of the pathogenesis, dissemination routes, and interaction with the host will help us to understand the rapid progression of the disease, which spreads to surrounding tissues increasing its morbidity and mortality due to the angioinvasive property of the fungus. We present the case of a 77 -year-old diabetic male with a diagnosis of rhinocerebral mucormycosis treated by maxillectomy and an antifungal scheme of amphotericin B. (Hosp Med Clin Manag. 2019;12:47-52)

Corresponding author: Álvaro Villegas-Cisneros, arthanyz@ hotmail.com
\end{abstract}

Key words: Rhinocerebal Mucormycosis. Diabetes mellitus. Maxillectomy. Fungal infection.

\section{RESUMEN}

La mucormicosis rinocerebral es una infección micótica oportunista letal. Es la presentación más común de dicha micosis, con una prevalencia mayor en pacientes diabéticos. Se origina en la mucosa de los senos paranasales después de la inhalación de las esporas del hongo. El estudio de la patogénesis, vías de diseminación e interacción con el huésped nos ayudará a comprender el rápido progreso de la enfermedad, cómo logra extenderse a tejidos circundantes, incrementando su morbilidad y mortalidad por la propiedad angioinvasiva del hongo. Se presenta el caso de un paciente del sexo masculino, diabético, de 77 años de edad con diagnóstico de mucormicosis rinocerebral tratada mediante maxilectomía y como esquema antifúngico, anfotericina B.

Palabras clave: Mucormicosis rinocerebal. Diabetes mellitus. Maxilectomía. Infección fúngica.

\section{CASE REPORT}

A 77-year-old man with a diagnosis of type 2 diabetes mellitus for 11 years was admitted to our hospital due to a periodontal abscess 1 week earlier, for which he was receiving antibiotic treatment. The main findings at physical examination were pain on palpation and an oral lesion in the purple palatal vault with ulcer (Fig. 1). The
Correspondencia:

*Álvaro Villegas-Cisneros

E-mail: arthanyz@ hotmail.com
Date of reception:05-07-2018

Date of acceptance: 23-11-2018

DOI: 10.24875/HMCM.18000138 
patient had dyspnea (90\% SAT), fever $\left(38^{\circ} \mathrm{C}\right)$, hypertension $(160 / 100 \mathrm{mmHg})$, and hyperglycemia on treatment with glibenclamide $5 \mathrm{mg}$ every $24 \mathrm{~h}$, referring poor adherence to treatment; he had systemic arterial hypertension for 11 years without medical treatment. He had a history of alcoholism daily until intoxication since he was 20 years old, suspending 27 years earlier; cerebrovascular disease 3 years ago with sequelae of mild left faciocorporal hemiparesis; and upper gastrointestinal tract bleeding secondary to esophagitis in 2016; he had a non-specified ischemic heart disease with unknown complications or sequelae and did not refer to have received treatment for this pathology.

The patient came to the Emergency Department of the ISSSTE's Regional Hospital "Gral. I. Zaragoza" referred from a second-level Medical Unit, with a periodontal abscess of 1-week duration, under antibiotic treatment. On admission, the patient presented with pain on palpation, dyspnea $(90 \% \mathrm{SAT})$, fever $\left(38^{\circ} \mathrm{C}\right)$, hyperglycemia (350 mg/dL), and arterial hypertension (160/100 $\mathrm{mm} / \mathrm{Hg}$ ). In the oral cavity, there was an extensive necrotic ulcerated lesion in the hard palate vault (Fig. 1). The patient was referred to the Maxillofacial Surgery Service, where a cytology of the lesion and a computed tomography (CT) were requested. The cytology showed the presence of hyphae and spores; the diagnosis of mucormycosis was confirmed by histology, which found branching hyphae compatible with zygomycetes in the tissue of the maxillary sinus (Fig. 2a). The CT findings (Fig. 2b) and the metabolic state of the patient further confirmed the diagnosis. Once the diagnosis and extension of the lesion were established, treatment with amphotericin B was started and a surgical procedure was decided. A maxillectomy was performed by a circumvestibular approach with LeFort 1 osteotomy by nasomaxillary, maxillomalar, and pterygomaxillary abutment resection for necrotic tissue debridement (Fig. 3). A bone reconstruction was performed with meshes for the orbital floor (Fig. 4). For wound closure, a polyester obturator mesh was placed. The surgical piece was preserved in physiological solution and cultured in Sabouraud and Mycosel media, in addition to routine anatomopathological studies.

After surgery, the patient was admitted to the intensive care unit (ICU) and was reported in a serious condition. After 5 days, the ICU requested reassessment by the Maxillofacial Surgery Service since the patient showed necrosis of the surgical sites' margins with active

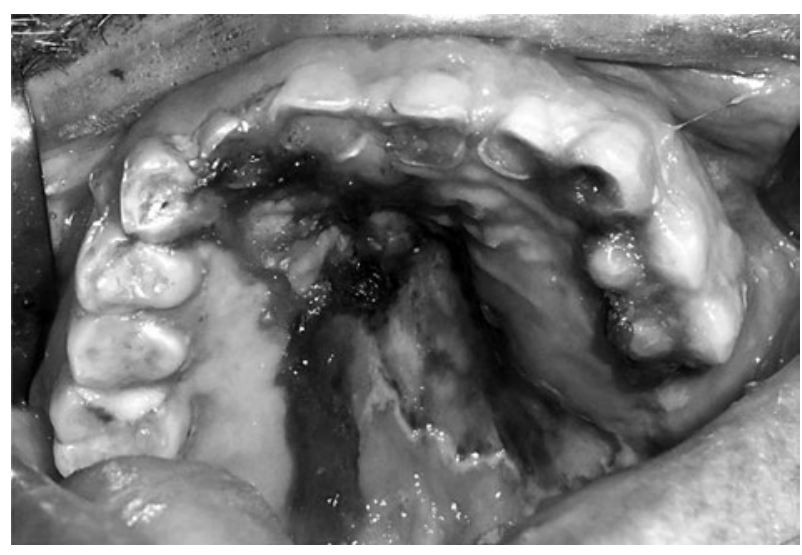

Figure 1. Initial lesion in the palatal area.

bleeding. A new surgery was decided for surgical scrubbing and debridement of necrotic areas with removal of the polyester obturator mesh. Days after the second operation, the patient had severe organ failure and died.

\section{MUCORMYCOSIS}

Mucormycosis is an opportunistic, angioinvasive, severe fungal infection caused by dimorphic fungi. These fungi belong to the class Zygomycetes, specifically the order Mucorales. This order is subdivided into several genera, with the most frequently isolated species being Rhizopus oryzae1. Other genera capable of causing this disease are Mucor, Cunninghamella, Apophysomyces, Lichtheimia (previously known as Absidia and Mycocladus), Saksenaea, and, less frequently, Rhizomucor. The first historical report of mucormycosis dates back to 1884 when Lichtheim investigated the pathogenicity of these fungi that were dispersed in the environment in a study conducted in immunocompromised rabbits ${ }^{2}$. In 1885, Paltauf created the term mucormycosis and was the first to report the case of a patient with a systemic fungal infection affecting the central nervous system. Some authors believe that the description of this case agreed with rhinocerebral mucormycosis; others believe that Paltauf was referring to disseminated gastrointestinal mucormycosis. It was not until 1964 when Emmos sustained that the case described by Paltauf was the first genuine case of mucormycosis, being disseminated mucormycosis ${ }^{3,4,5}$. In 1943, Gregory et al. described the first case of rhino-orbito-cerebral mucormycosis, and after 14 years, Baker reported a dozen cases of the same presentation of mucormycosis. Finally, in 1955, 


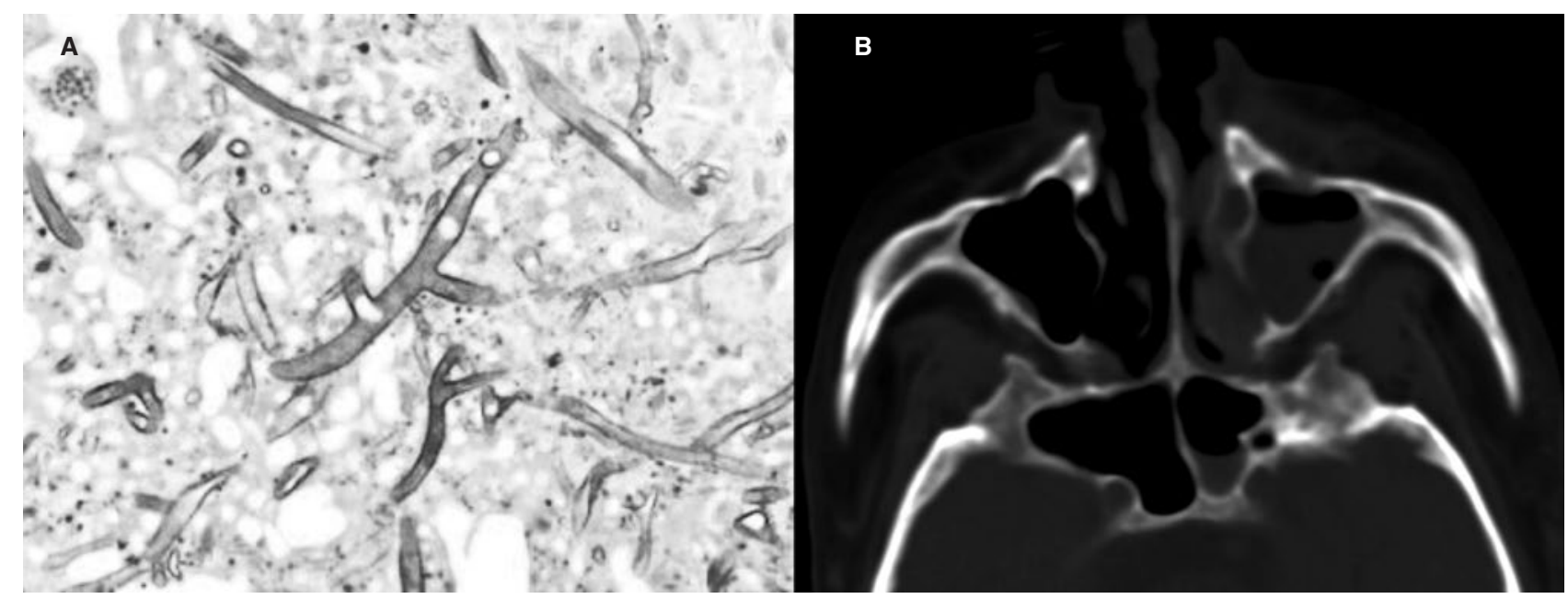

Figure 2. A: Photomicrograph showing long, broad, non-septate, irregularly folded mucormycosis hyphae branching at broad angles. B: Computed tomography axial section showing occupation of the sinuses, maxillary sinus, and sphenoid sinus on the left side.

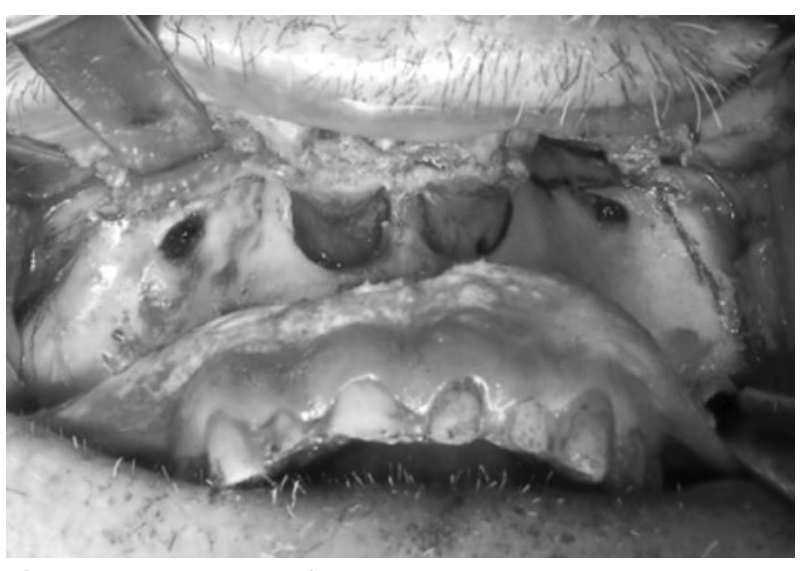

Figure 3. Delimitation of the surgical margins.

Harris reported the first case of a patient who survived rhinocerebral mucormycosis ${ }^{3,5}$.

Mucormycosis is the third most important invasive mycosis after candidiasis and aspergillosis ${ }^{6}$. Rhino-orbital-cerebral mucormycosis is the most common presentation of this mycosis, with a higher prevalence in diabetic patients. In the past, mucormycosis was considered a rare infection, associated with diabetic patients with ketoacidosis. Currently, it is known that mucormycosis can occur in any immunocompromised patient. According to the largest published epidemiological comparative study, diabetes is the main predisposing factor ${ }^{7}$. The number of diabetic, transplanted, and immunocompromised patients who may be exposed to the fungus has increased and so has the incidence of the disease. Only considering diabetes, the World Health Organization reports an increase from 108 million patients diagnosed with diabetes in 1980 to 422

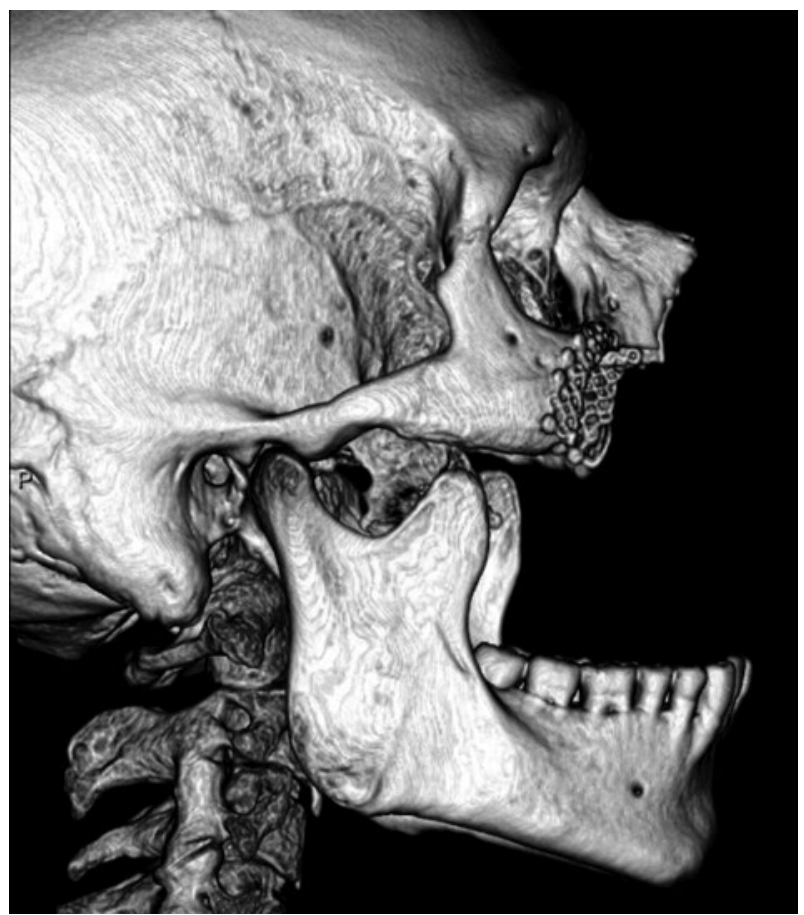

Figure 4. Computed tomography three-dimensional reconstruction showing bone reconstruction using titanium meshes for orbital floor.

million in 20148; of them, and $8.3-13 \%$ will be at risk of acquiring rhinocerebral mucormycosis, as estimated by Petrikkos et al., using the maximum-likelihood estimate method $^{6-8}$. In Mexico, Corzo et al. (2018) conducted an epidemiological study of cases reported between 1982 and 2016. Among 418 cases identified, 72\% were diabetic patients and $75 \%$ presented with sinusitis. The mortality rate was $51 \%$. Rhizopus spp. were the most frequent isolates (59\%). The authors conclude that 
diabetes mellitus is the most common risk factor for mucormycosis in Mexico and that the early identification of signs and symptoms is necessary to prevent the progression of this disease ${ }^{9}$.

\section{Pathophysiology}

The pathogenesis of mucormycosis will depend on host factors. Fungi of the zygomycetes class do not have the capacity to proliferate in patients under normal immunological conditions since macrophages and tissue neutrophils as the initial line of defense have the ability to phagocyte the fungus ${ }^{10}$. Mucormycosis is an opportunistic mycosis that mainly attacks immunocompromised individuals; although, in these patients, the primary line of defense will also try to arrest the infection, this attempt will be unsuccessful, activating the decoy family receptors (toll-like receptor) that will start a common inflammatory response. This inflammatory response is diminished, and phagocytosis cannot be carried out since chemotaxis, oxidative, and non-oxidative mechanisms are defective ${ }^{11}$, predisposing to the establishment of infection.

Mucormycosis is characterized by hematogenous dissemination, which occurs due to the angioinvasive property of the fungi, resulting in thrombosis and tissue necrosis. The causative fungus can penetrate endothelial cells, through adhesion to type IV collagen from the lamina of the extracellular matrix of endothelial cells inducing endocytosis ${ }^{11}$. Under normal conditions, iron is a necessary mineral for the development of the body, for biological functions such as oxygen transport, respiration, and cell growth. Once the Mucorales are inside the vessels, the increase in free iron radicals in the blood predisposes the fungi to grow and spread since these fungi produce the enzyme rizoferrin which will uptake the iron from the host to provide the fungus with adaptation mechanisms. Besides this mechanism, the fungi produce deferoxamine and obtain ferrum from the heme group through the heme oxygenase.

The means of mucormycosis dissemination are facilitated in diabetes. To consider its pathophysiology, the metabolic state of a diabetic patient should be considered first. Diabetes mellitus is an endocrine-metabolic disease caused by an absolute or relative deficiency in the action of insulin, affecting the metabolism of glycosides, lipids, and proteins ${ }^{12}$. High blood glucose levels will cause endothelial damage that will be expressed as microangiopathy or macroangiopathy, causing metabolic decompensation expressed as hypertension, renal failure, peripheral arterial disease, and diabetic retinopathy $^{13}$.

It was previously thought that ketoacidosis was the main predisposing factor for mucormycosis in a diabetic patient. However, although ketoacidosis provides an acid medium for fungal proliferation, it is now known that hyperglycemia, with high levels of iron in the blood and endothelial dysfunction due to endothelial damage caused by microangiopathy and macroangiopathy, will prevent the diabetic patient from displaying an adequate inflammatory response. The inflammatory response is affected by phagocytic dysfunction and caused by oxidative stress. Endothelial dysfunction causes an increase in the glucose regulatory protein 78 , which acts as a mediator receptor inducing the penetration of Mucorales to the endothelium; for this reason, mucormycosis can also occur in compensated diabetic patients ${ }^{11,14}$

\section{Diagnosis}

Although rhino-orbital-cerebral mucormycosis is an extremely lethal infection, its prognosis is highly related to the diagnosis, treatment, and metabolic state of the patient. This type of mycosis is caused by inhalation of fungal spores, which are inoculated into the nasal or oral mucosa, the nasal being the most common. Here, the spores rapidly reproduce and disseminate to neighboring tissues. Once the paranasal sinuses are invaded, the infection tends to expand through the palate, sphenoid sinus, the cavernous sinus, surrounding the orbits until it reaches the base of the skull, and extends either through the orbital fissure or the ethmoidal bone ${ }^{15}$.

The clinical diagnosis will be made through the symptoms, which may be ophthalmic (ophthalmoplegia, chemosis, eyelid necrosis, and endophthalmitis) and non-ophthalmic (sinusitis, facial and palatal necrosis, dental pain, fever, and epistaxis). The symptoms will be related to the extension of the infection. When there are ophthalmic symptoms, the infection affects the orbit and skull base. If only non-ophthalmic symptoms are present, the infection is thought to involve the paranasal sinuses and palate, which would, in general, have a better prognosis. According to Vargas et al., the clinical diagnosis of mucormycosis should be suspected when at least two of the following parameters are met $^{16}$ : (1) 
Large areas of necrosis on the hard palate, nostrils, nasal tip, black or brown nasal discharge, and epistaxis, (2) metabolic disease, (3) immunosuppressive disease, (4) immunosuppressive drug therapy, (5) neurological alterations, and (6) facial alterations.

The imaging diagnosis is based on CT and magnetic resonance imaging (MRI). In the $\mathrm{CT}$, there will be data of pansinusitis and paranasal sinus occupation will be visible, whether unilateral or bilateral; the bone tissue can be seen undamaged in the initial stages, although bone destruction may also be observed. In advanced stages of bone necrosis, it has been referred to as an appearance of moth-eaten bone ${ }^{16}$. MRI will be very useful to estimate the extension of the lesion when the infection involves the orbit and skull base. As in the MRI, signs such as proptosis will be visible.

Although mucormycosis may be suspected clinically, supported by the imaging studies, before starting antifungal treatment and proceeding to surgical treatment, the microbiological diagnosis should be established. Samples from the lesion should be cultured in agar: blood agar, Sabouraud agar, inhibitory mold agar, and dextrose and potato agar, at $25-55^{\circ} \mathrm{C}$; results will be obtained in approximately 3-7 days confirming the diagnosis ${ }^{17}$. To avoid a delay in treatment that could worsen the prognosis, a biopsy of infected soft tissues can be performed, in which the asexual structures of the hyphae are identified ${ }^{18}$. Once the diagnosis and extension of the lesion have been established, the prognosis will be predictable; when the lesion has spread to the orbit, brain damage will occur in $45 \%$ of cases, in which case the mortality is $73 \%{ }^{18}$.

\section{Treatment}

The treatment of choice in mucormycosis is antifungal therapy with extensive surgical debridement. Four cardinal points should be considered to eradicate the infection: (1) Prompt diagnosis, (2) control of predisposing factors, (3) appropriate surgical debridement, and (4) adequate antifungal therapy. In the literature, amphotericin $B$ is the antifungal agent of choice, being its use limited due to nephrotoxicity; however, it is the only antifungal agent in infections by Mucorales. The use of liposomal amphotericin B has been described, which is less nephrotoxic, but it is extremely expensive and difficult to obtain in our country. There is another variation of amphotericin called amphotericin B lipid complex, which has been described to treat some strains of $\mathrm{Mu}$ corales although with insufficient experimentation in humans. The development of new therapies has been extremely restricted since mucormycosis does not represent a disease of global importance, and pharmaceutical companies would rather invest in other more commercial drugs ${ }^{18}$. Surgical treatment is based on the extensive debridement of the necrotic tissue until bleeding tissue is found ${ }^{19}$. Maxillectomy and orbitomaxillary resection have been described for rhinocerebral mucormycosis.

\section{DISCUSSION}

The metabolic state of a diabetic patient offers favorable conditions for the development of the fungi causing mucormycosis. Diabetic ketoacidosis was considered a crucial predisposing factor since hyperglycemia, metabolic acidosis, and ketonemia with cetonuria, promoting the production by the fungus of an acid protease that allows for rapid growth, in addition to a characteristic active keto-reductase enzymatic system of the Mucorales ${ }^{17,18,19}$. Mucormycosis was found to occur as well in decompensated diabetic patients without ketoacidosis and compensated immunocompetent diabetic patients. It was previously acknowledged that this mycosis was present in decompensated patients due to high blood glucose levels; however, although it is true that Mucorales fungi have an affinity for an acidic $\mathrm{pH}$, they will also be able to develop an optimum acid medium for their growth, consuming high glucose levels ${ }^{19}$. Considering that this disease may occur in compensated diabetic patients, to understand its pathophysiology, the metabolic state of a diabetic patient should be considered, in addition to understanding the interaction of the fungus with the host's endothelium and how it acquires its pathogenicity within the body, resulting in the angioinvasive nature of the infection. When this mechanism is known, it will be easier to provide an optimal treatment that improves the prognosis of patients suffering from this fungal infection.

\section{CONCLUSIONS}

Mucormycosis is a disease with a high mortality rate. If the patient survives the treatment, it has devastating esthetic and functional sequelae. The antifungal drugs are highly nephrotoxic, which usually leaves additional 
sequelae. Although the fungi that cause mucormycosis are dispersed in the environment and can be found in bread molds and fruits, mucormycosis may be even nosocomially acquired and may be associated to therapeutic immunosuppression. The fungi have been found in adhesive tapes, bandages, medication patches, and even tongue depressors ${ }^{19,20}$. The increase in the worldwide prevalence of diabetes and immunosuppression associated to organ transplantation and cancer treatment, along with the constant exposure to the fungus, is causing an increase in mucormycosis cases, which requires a greater awareness among health professionals of this infection and the need for its prompt diagnosis and treatment. The prognosis of a patient with rhinocerebral mucormycosis is uncertain, and unfortunately, the mortality rate is high.

\section{REFERENCES}

1. Spellberg B, Edwards J Jr., Ibrahim A. Novel perspectives on mucormycosis: pathophysiology, presentation, and management. Clin Microbiol Rev. 2005;18:556-69.

2. Smith HW, Kirchner JA. Cerebral mucormycosis; a report of three cases. AMA Arch Otolaryngol. 1958;68:715-26.

3. Apáez OJ, Villasana JE, Hernández J. Hemimaxilectomía en mucormicosis rinocerebral. Caso Clín Rev Odontol Mex. 2009;13:47-52.

4. Baker RD. Mucormycosis. In: The Pathologic Anatomy of Mycoses. HeideIberg, Berlin: Springer; 1971. p. 832-918.
5. Romero-Zamora JL, Bonifaz A, Sánchez CJ, Lagunas-Ramírez A, HidalgoLoperena H. Mucormicosis rinocerebral. Rep Doce Casos Rev Med Hosp Gen Mex. 2000;63:178-84.

6. Petrikkos G, Skiada A, Lortholary 0 , et al. Epidemiology and clinical manifestations of mucormycosis. Clin Infect Dis. 2012;54 Suppl 1:S23-34.

7. Roden MM, Zaoutis TE, Buchanan WL, et al. Epidemiology and outcome of zygomycosis: a review of 929 reported cases. Clin Infect Dis. 2005;41:634-53.

8. World Health Organization. Definition, Diagnosis and Classification of Diabetes Mellitus and Its Complications: report of a WHO Consultation; Part 1: diagnosis and Classification of Diabetes Mellitus. Geneva, Switzerland: World Health Organization; 2006.

9. Corzo-León DE, Chora-Hernández LD, Rodríguez-Zulueta AP, Walsh TJ. Diabetes mellitus as the major risk factor for mucormycosis in mexico: epidemiology, diagnosis, and outcomes of reported cases. Med Mycol. 2018;56:29-43.

10. Kumar V, Abbas AK, Aster JC. Robbins Basic Pathology. Chicago: Elsevier Health Sciences; 2012.

11. Ibrahim AS, Spellberg B, Walsh TJ, Kontoyiannis DP. Pathogenesis of mucormycosis. Clin Infect Dis. 2012:54 Suppl 1:S16-22.

12. Soca PE, Bahr AP, Niño S. Mecanismos moleculares del daño microvascular de la diabetes mellitus. Correo Cient Méd Holguín. 2004;8:1-11.

13. American Diabetes Association. Diagnosis and classification of diabetes mellitus. Diabetes Care. 2012;35 Suppl 1:S64-71.

14. Mayayo E, Klock C, Goldani LZ, Monteiro AC, Capilla J. Infección múltiple fúngica en un paciente diabético. Rev Iberoam Micol. 2010;27:140-3.

15. Bhansali A, Bhadada S, Sharma A, et al. Presentation and outcome of rhinoorbital-cerebral mucormycosis in patients with diabetes. Postgrad Med J. 2004;80:670-4

16. Bonifaz A, Macias B, Paredes-Farrera F, et al. Palatal zygomycosis: experience of 21 cases. Oral Dis. 2008;14:569-74.

17. Prabhu RM, Patel R. Mucormycosis and entomophthoramycosis: a review of the clinical manifestations, diagnosis and treatment. Clin Microbiol Infect. 2004:10 Suppl 1:31-47.

18. Ciesla MC, Kammeyer PL, Yeldandi V, Petruzzelli GJ, Yong SL. Identification of the asexual state of Rhizopus species on histologic tissue sections in a patient with rhinocerebral mucormycosis. Arch Pathol Lab Med. 2000;124:883-7.

19. Manrique H, Calderón J, Soto A, et al. Cetoacidosis diabética: una complicación frecuente de la diabetes Tipo 2 en hispanoamericanos. Avian Diabetol. 2003;19:141-7

20. Henao CS, de Stouvenel AR, Kousen JE. Características de la producción de la renina microbiana de Mucor miehei en un proceso de alimentación por lote. Rev Colomb Biotecnol. 1999;2:28-34. 